Original Research

\title{
Use of Zebra Fish Eggs as Early Indicators of Aquatic Environmental Pollution
}

\author{
Crina Laura Moșneang', Eugenia Dumitrescu', Florin Muselin², \\ Valentin Ciulan $^{3}$, Adrian Grozea ${ }^{4}$, Romeo Teodor Cristina ${ }^{1 *}$ \\ 'Department of Pharmacology and Pharmacy, Faculty of Veterinary Medicine \\ ${ }^{2}$ Department of Toxicology, Faculty of Veterinary Medicine \\ ${ }^{3}$ Department of Medical Pathology, Faculty of Veterinary Medicine \\ ${ }^{4}$ Department of Aquaculture, Faculty of Animal Science and Biotechnology \\ Banat's University of Agriculture and Veterinary Medicine "King Michael I of Romania" from Timișoara, Romania
}

Received: May 12, 2015

Accepted: June 23, 2015

\begin{abstract}
Our study used mortality and developmental abnormalities present in fertilized zebra fish eggs as a possible useful bio-indicator to assess water pollution from the vicinity of five great swine units using 48-hour in vitro zebra fish eggs acute toxicity test. In assay, 1,300 (Test) and 220 (Control) healthy fertilized zebra fish eggs were used. During the test duration, a number of dead eggs or embryos and/or any other disturbance in the embryonic development that could indicate pollution were ascertained. In parallel, embryonic mortality was assessed for each swine unit possible farm effluent source, using double samples and 10 different water dilutions provided from the environs river. It was found in some situations that fertilized fish egg development was disturbed by the water components at the assay moment. Statistical results, analyzed according to the Kolmogorov-Smirnov normality test (significant $\mathrm{P}<0.05$, or lower), revealed that, from the five observed units at the sample collection moment, the river water was polluted in the surroundings of swine Units 1 and 4 , which was also confirmed by the acute toxicity endpoints presence in developed embryos in the water samples provided. This qualitative assay could be a helping tool for small-scale environmental risk assessment due to the opportunity to achieve, in a short amount of time, an accurate analysis.
\end{abstract}

Keywords: aqua-pollution, eco-risk-method, farm effluents, Danio rerio, fertilized eggs

\section{Introduction}

Zebra fish adults and embryos are increasingly used in toxicology and, especially, eco-toxicology as reliable diagnostic and experimental models in order to test various substances - from pollutants to active medicinal substances. In this aim the zebra fish eggs and embryo assays can provide an easily available, low-cost option that can offer enough accurate results in a limited time and therefore being able to be replicated rapidly [1-10].

*e-mail: rtcristina@yahoo.com
Toxicity effects of diverse components from wastewaters can be highlighted by the changes in the anatomical and ethologic development of the zebra fish embryonic and larval stages. Also, their eggs could be used, with promising outcomes, in the pollution hazard and risk assessments, because of their unique qualities: transparency, lack of adhesion, reduced diameter, egg availability, and ease of method reproducibility [11-14].

Another notable advantage of this testing methodology is that, according to European welfare regulations, zebra fish embryo testing is categorized as an in vitro testing and thus not subject to animal protection legislation $[15,16]$. 
Table 1. Characteristics of water samples and sampling conditions.

\begin{tabular}{|c|c|c|c|c|c|c|c|c|c|c|}
\hline Water samples & S1 & S2 & S3 & S4 & S5 & S6 & S7 & S8 & S9 & S10 \\
\hline \multicolumn{11}{|l|}{ GPS coordinates of the units: } \\
\hline Longitude & $45^{\circ} 62^{\prime} 75^{\prime \prime}$ & $45^{\circ} 45^{\prime} 6^{\prime \prime}$ & $45^{\circ} 45^{\prime} 6^{\prime \prime}$ & $45^{\circ} 46^{\prime} 66^{\prime \prime}$ & $45^{\circ} 51^{\prime} 65^{\prime \prime}$ & $45^{\circ} 46^{\prime} 66^{\prime \prime}$ & $45^{\circ} 45^{\prime} 6^{\prime \prime}$ & $45^{\circ} 51^{\prime} 65^{\prime \prime}$ & $45^{\circ} 45^{\prime} 6^{\prime \prime}$ & $45^{\circ} 62^{\prime} 75^{\prime \prime}$ \\
\hline Latitude & $21^{\circ} 1 ' 30^{\prime \prime}$ & $21^{\circ} 1^{\prime} 05^{\prime \prime}$ & $21^{\circ} 1^{\prime} 66^{\prime \prime}$ & $21^{\circ} 13^{\prime \prime}$ & $21^{\circ} 1^{\prime} 49^{\prime \prime}$ & $21^{\circ} 13^{\prime \prime}$ & $21^{\circ} 1^{\prime} 66^{\prime \prime}$ & $21^{\circ} 1^{\prime} 49^{\prime \prime}$ & $21^{\circ} 1^{\prime} 05^{\prime \prime}$ & $21^{\circ} 10^{\prime \prime}$ \\
\hline Water temperature $\left({ }^{\circ} \mathrm{C}\right)$ & 8.2 & 7.1 & 7.0 & 6.4 & 7.8 & 9.7 & 8.1 & 9.4 & 8.8 & 6.9 \\
\hline Ambient temperature $\left({ }^{\circ} \mathrm{C}\right)$ & 3 & 3 & 3 & 3 & 3 & 7 & 7 & 8 & 7 & 7 \\
\hline Atmospheric pressure $(\mathrm{hPa})$ & 1,048 & 1,048 & 1,048 & 1,048 & 1,048 & 1,012 & 1,012 & 1,012 & 1,012 & 1,012 \\
\hline Weather condition & \multicolumn{5}{|c|}{ Light rain } & \multicolumn{5}{|c|}{ Cloudy sky } \\
\hline Relative humidity (\%) & 98 & 97 & 98 & 98 & 98 & 63 & 63 & 63 & 63 & 63 \\
\hline Conductivity $\left(\mu \mathrm{S} \cdot \mathrm{cm}^{-1}\right)$ & 142.5 & 458.2 & 496.7 & 403.5 & 679.9 & 460.8 & 538.0 & 730.7 & 509.0 & 109.2 \\
\hline Salinity $\left(\mathrm{mg} / \mathrm{dm}^{3}\right)$ & 61.0 & 262.0 & 225.0 & 262.0 & 265.0 & 221.0 & 255.0 & 351.0 & 242.0 & 51.0 \\
\hline $\mathrm{pH}$ & 7.5 & 8.7 & 8.2 & 8.3 & 8.0 & 7.1 & 7.5 & 7.7 & 8.6 & 7.9 \\
\hline Dissolved oxygen $\left(\mathrm{mg} / \mathrm{dm}^{3}\right)$ & 4.9 & 4.4 & 4.7 & 5.9 & 4.7 & 7.34 & 4.62 & 9.45 & 9.75 & 11.66 \\
\hline Chlorides $\left(\mathrm{mg} / \mathrm{dm}^{3}\right)$ & 38 & 21 & 31 & 65 & 12 & 50 & 100 & 120 & 130 & 150 \\
\hline Nitrates $\left(\mathrm{mg} / \mathrm{dm}^{3}\right)$ & 1.59 & 1.87 & 1.72 & 1.90 & 1.91 & 1.79 & 4.20 & 4.07 & 4.10 & 4.05 \\
\hline Phosphates (mg/dm³) & 0.035 & 0.017 & 0.022 & 0.017 & 0.024 & 0.017 & 0.005 & 0.005 & 0.008 & 0.006 \\
\hline
\end{tabular}

In areas where an intensive swine industry is developing rapidly and the threat of eco-pollution with farm effluents can become a reality [17-19] due, in part, to the lack of more severe legislation, the periodical quality inspection and monitoring of the river waters from the vicinity of swine farms can be a helpful early risk assessment tool for eco-toxicology and public health domains.

In this respect the aim of the present study was to imagine and follow a 48-hour acute toxicity test using zebra fish eggs as early indicators of possible aquatic environmental pollution with effluents from the vicinity of the five greatest swine farms in Timiş County, Romania, in conformity to EN ISO 15088:2007 embryo assay methodology.

\section{Materials and Methods}

\section{The Units}

The study is a part of a greater soil and water eco-risk study and was carried out in the five greatest swine units in Timiș County, Romania, where - with more than one million swine per year - can be found the biggest integrated intensive swine producer in Romania, where the possibility of pollution from farm effluents could easily become an eco-problem. The water samples were obtained from rivers in the vicinity of these units. From the nearest point to water source, the location coordinates and main measured physico-chemical parameters of sampled waters are presented in Table 1.

\section{Test Methodology}

In order to produce fresh fertilized eggs, healthy zebra fish, aged between 10 and 12 months, and not subjected to any pharmaceutical treatment or study (acute or prophylactic) were used. A lighting period of $16 \mathrm{~h} \mathrm{light} / 8 \mathrm{~h}$ dark was maintained during the entire experiment. Fresh fertilized eggs, differentiated in the first hour after spawning were used, and following, embryos were observed using an LCD microscope (Celestron LCD 44340, USA) to the $\times 10$ and $\times 40$ magnifications.

Initially all freshly fertilized eggs presented a perivitelline space, containing the nucleus surrounded by yolk membrane, the germinal centre being present at the apical pole of the nucleus and then the first cell division was observed generally after 15 minutes at $26^{\circ} \mathrm{C}$.

As a result, the germination disc divided in 4 (after cell division stage 4 , fertilized eggs could be easily differentiated by the non-fertilized ones), 8, 16, and 32 blastomeres, respectively.

During testing, healthy 1,300 Test (T) and 220 Control (C) freshly fertilized zebra fish eggs were used following EN ISO 15088:2007 methodology. For analysis, 10 consecutive dilutions $-1 \times, 2 \times, 3 \times, 4 \times, 6 \times, 8 \times, 12 \times, 16 \times, 24 \times$, and $32 \times-$ of $40 \mathrm{~mL}$ initial sampled river water were used, and from dilutions $2 \mathrm{~mL}$ were transferred into wells.

A single embryo was transferred in each well, to which was added the measured quantity of $2 \mathrm{~mL}$ test water according to each dilution, and for each water sample concentration a minimum of 10 healthy fertilized eggs were used. 
Table 2. Comparative embryo-lethality on the studied samples.

\begin{tabular}{|c|c|c|c|c|c|c|c|c|c|c|}
\hline Samples & \multicolumn{2}{|c|}{ S5/S7 } & & & \multicolumn{2}{|c|}{$\mathrm{S} 1 / \mathrm{S} 11$} & \multicolumn{2}{|c|}{$\mathrm{S} 3 / \mathrm{S} 10$} & \multicolumn{2}{|c|}{ S6/S9 } \\
\hline \multirow{2}{*}{ Dilutions } & \multicolumn{10}{|c|}{ Dead embryos } \\
\hline & \multicolumn{10}{|c|}{ No./\% } \\
\hline \multirow{2}{*}{$1 \times$} & 1 & 4 & 4 & 2 & 4 & 4 & 3 & 1 & 3 & 3 \\
\hline & $8 \%$ & $33 \%$ & $33 \%$ & $17 \%$ & $33 \%$ & $33 \%$ & $25 \%$ & $8 \%$ & $25 \%$ & $25 \%$ \\
\hline \multirow{2}{*}{$2 \times$} & 1 & 6 & 5 & 3 & 5 & 7 & 5 & 6 & 3 & 4 \\
\hline & $8 \%$ & $50 \%$ & $42 \%$ & $25 \%$ & $42 \%$ & $58 \%$ & $42 \%$ & $50 \%$ & $25 \%$ & $33 \%$ \\
\hline \multirow{2}{*}{$3 \times$} & 3 & 3 & 4 & 3 & 21 & 2 & 2 & 3 & 2 & 1 \\
\hline & $25 \%$ & $25 \%$ & $33 \%$ & $25 \%$ & $7 \%$ & $17 \%$ & $17 \%$ & $25 \%$ & $17 \%$ & $8 \%$ \\
\hline \multirow{2}{*}{$4 \times$} & 3 & 3 & 2 & 5 & 3 & 4 & 5 & 1 & 2 & 4 \\
\hline & $25 \%$ & $25 \%$ & $17 \%$ & $42 \%$ & $25 \%$ & $33 \%$ & $42 \%$ & $8 \%$ & $17 \%$ & $33 \%$ \\
\hline \multirow{2}{*}{$6 \times$} & 3 & 4 & 3 & 2 & 5 & 4 & 2 & 3 & 3 & 3 \\
\hline & $25 \%$ & $33 \%$ & $25 \%$ & $17 \%$ & $42 \%$ & $33 \%$ & $17 \%$ & $25 \%$ & $25 \%$ & $25 \%$ \\
\hline \multirow{2}{*}{$8 \times$} & 3 & 3 & 5 & 3 & 4 & 1 & 4 & 2 & 3 & 3 \\
\hline & $25 \%$ & $25 \%$ & $42 \%$ & $25 \%$ & $33 \%$ & $8 \%$ & $33 \%$ & $17 \%$ & $25 \%$ & $25 \%$ \\
\hline \multirow{2}{*}{$12 \times$} & 3 & 5 & 1 & 1 & 4 & 2 & 2 & 5 & 1 & 2 \\
\hline & $25 \%$ & $42 \%$ & $8 \%$ & $8 \%$ & $33 \%$ & $17 \%$ & $17 \%$ & $42 \%$ & $8 \%$ & $17 \%$ \\
\hline \multirow{2}{*}{$16 \times$} & 4 & 4 & 1 & 3 & 3 & 1 & 1 & 4 & 3 & 4 \\
\hline & $33 \%$ & $33 \%$ & $8 \%$ & $25 \%$ & $25 \%$ & $8 \%$ & $8 \%$ & $33 \%$ & $25 \%$ & $33 \%$ \\
\hline \multirow{2}{*}{$24 \times$} & 2 & 2 & 2 & 2 & 4 & 3 & 3 & 2 & 3 & 4 \\
\hline & $17 \%$ & $17 \%$ & $17 \%$ & $17 \%$ & $33 \%$ & $25 \%$ & $25 \%$ & $17 \%$ & $25 \%$ & $33 \%$ \\
\hline \multirow{2}{*}{$32 \times$} & 2 & 5 & 2 & 2 & 2 & 2 & 3 & 4 & 3 & 3 \\
\hline & $17 \%$ & $42 \%$ & $17 \%$ & $17 \%$ & $17 \%$ & $17 \%$ & $25 \%$ & $33 \%$ & $25 \%$ & $25 \%$ \\
\hline
\end{tabular}

Per each 24-well culture plate (Thermo Fisher Scientific, USA), two dilutions (20 wells) and the corresponding control samples (4 wells), which consisted of system water, were distributed. After $48 \mathrm{~h}$ exposure of the freshly fertilized eggs, concentration in which no toxic effect could be observed was determined. In conformity to ISO methodology, the acute toxicity main end points in zebra fishobtained embryos to be ascertained were: lack of tail detachment, heartbeat absence, and coagulated eggs [20].

\section{Statistics}

The results were analyzed with the KolmogorovSmirnov (K-S) normality test, a non-parametric test for the equality of continuous, one-dimensional probability distributions that compare one or two samples with a reference probability distribution. The K-S test is one of the most useful for comparing two samples, as it is sensitive to differences in both location and shape of the empirical cumulative distribution functions of the two samples, the results being considered significant when $\mathrm{P}<0.05$ or lower.

\section{Results}

\section{Eco-Test of Water Samples from Unit 1 Vicinity}

Water samples from Unit 1 vicinity were labeled S4 and S6, and the results of embryo testing were interpreted by making a correlation between them. The highest mortality was registered in dilution $2 \times$ followed closely by dilution $12 \times$ for sample S6. In control dilutions, embryos died at dilution $4 \times$ and $32 \times$ and just for sample S4. For dilutions $3 \times, 4 \times, 16 \times$, and $24 \times$ the number of dead embryos was found to be identical for both samples.

\section{Eco-Test of Water Samples from Unit 2 Vicinity}

Water samples from Unit 2 vicinity, labeled S3 and S7, revealed a high embryonic mortality for sample $\mathrm{S} 3$ at dilutions $2 \times$ and $8 \times$, and for sample S7 at dilution $4 \times$. A low mortality was recorded for sample S3 at dilutions $12 \times$ and $16 \times$, and for sample S7 for dilution $12 \times$. The number of dead embryos was identical for both samples collected at dilutions $12 \times, 24 \times$, and $32 \times$. 

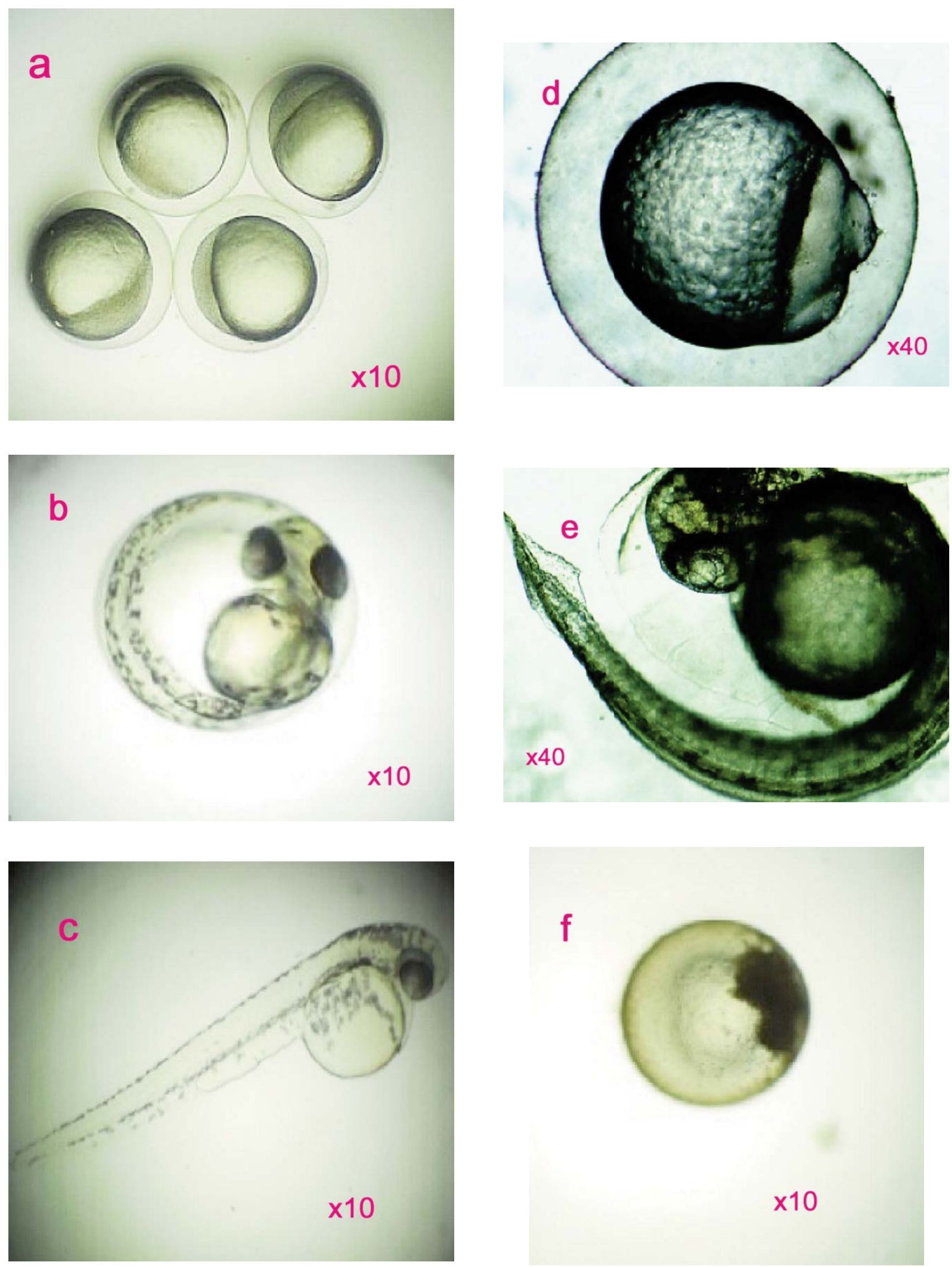

Fig. 1. Normal vs. abnormal aspects of embryo developments found in assay. 

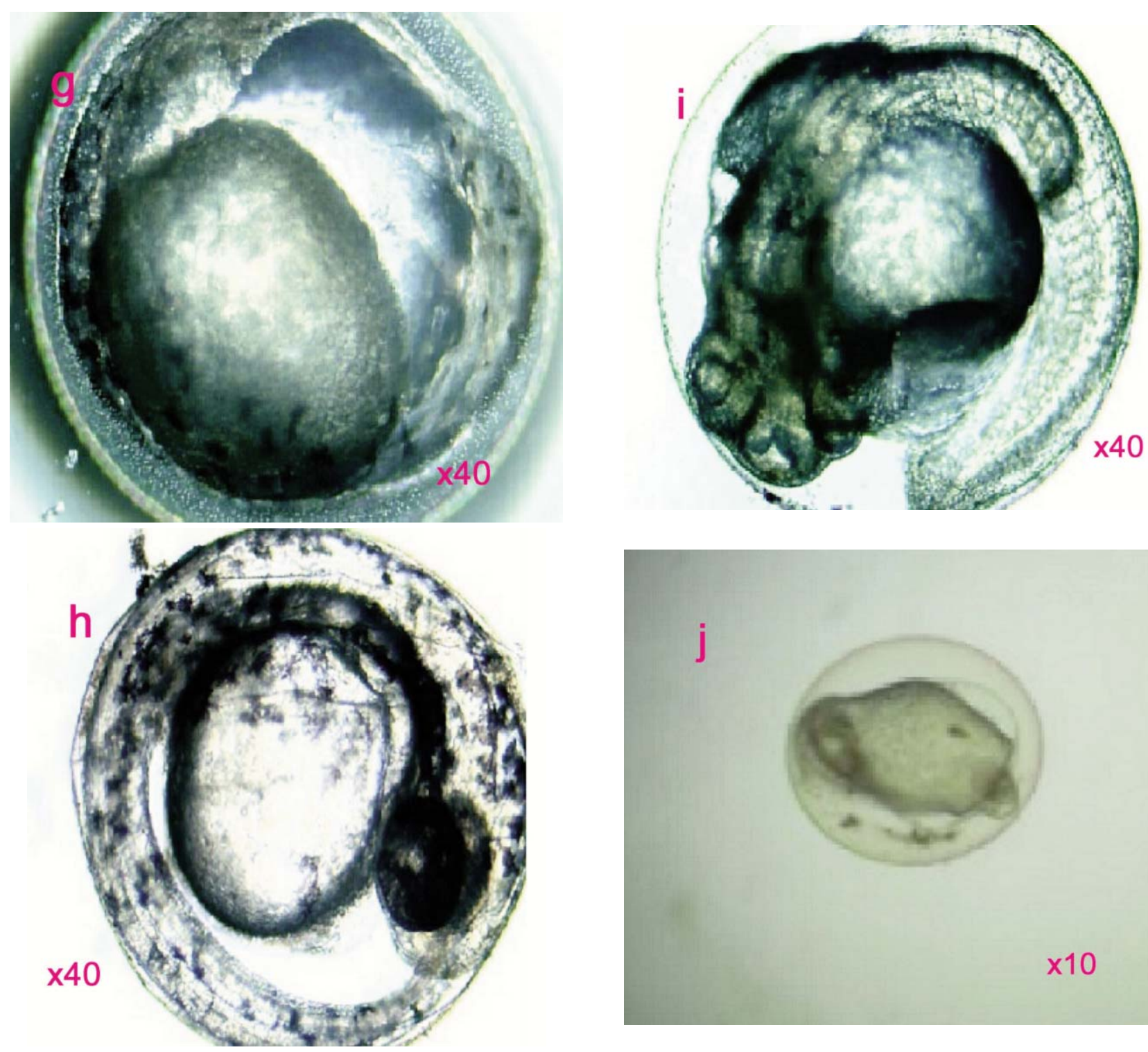

Fig. 1. Continued.

\section{Eco-Test of Water Samples from Unit 3 Vicinity}

For the samples taken from the Unit 3 area (S1 and $\mathrm{S} 10$ ), the greatest mortality rate was observed for sample S10 at $2 \times$ dilution, and for sample S1 at dilutions $2 \times$ and $6 \times$. The lowest mortality rate found was for sample S10 at dilutions $8 \times$ and $16 \times$, while for sample S1 at dilutions $3 \times$ and $32 \times$. Identical values for embryonic mortality were observed for both samples at dilutions $1 \times, 3 \times$, and $32 \times$.

\section{Eco-Test of Water Samples from Unit 4 Vicinity}

Samples taken in the vicinity of Unit 4 were labeled S2 and S9. High values of mortality were recorded for sample S9 at dilutions $2 \times$ and $12 \times$, and for sample S2 for dilutions $2 \times, 4 \times$, and $8 \times$. A low mortality rate was observed for sample $\mathrm{S} 9$ at dilutions $1 \times$ and $3 \times$, and for sample $\mathrm{S} 2$ at a dilution of $16 \times$. No similar mortality values were found for S2 and $\mathrm{S} 9$ samples.

\section{Eco-Test of Water Samples from Unit 5 Vicinity}

Samples taken from water courses in the vicinity of Unit 5 (S5 and S8) registered the highest mortality for sample S8 at dilutions $2 \times, 4 \times, 16 \times$, and $24 \times$, and for sample S5 at dilutions $1 \times, 2 \times, 6 \times, 8 \times, 16 \times, 24 \times$, and $32 \times$. The lowest values recorded were for sample S8 at dilution $3 \times$ and for sample S5 at dilution $12 \times$. Identical values for mortality in both samples were identified for dilutions $1 \times, 6 \times, 8 \times, 16,24 \times$, and $32 \times$.

The embryonic lethality assessed by us revealed a link between the numbers of dead embryos at the same concentration for different samples taken from the same water source.

The microscopic images of embryos helped us to ascertain that the development of the freshly fertilized eggs was clearly disturbed by the water components at the moment of analysis. The main observed abnormalities were: fish embryos with small hemorrhagic spots in the thoracic cavity, blocked embryo development, the rugged appear- 

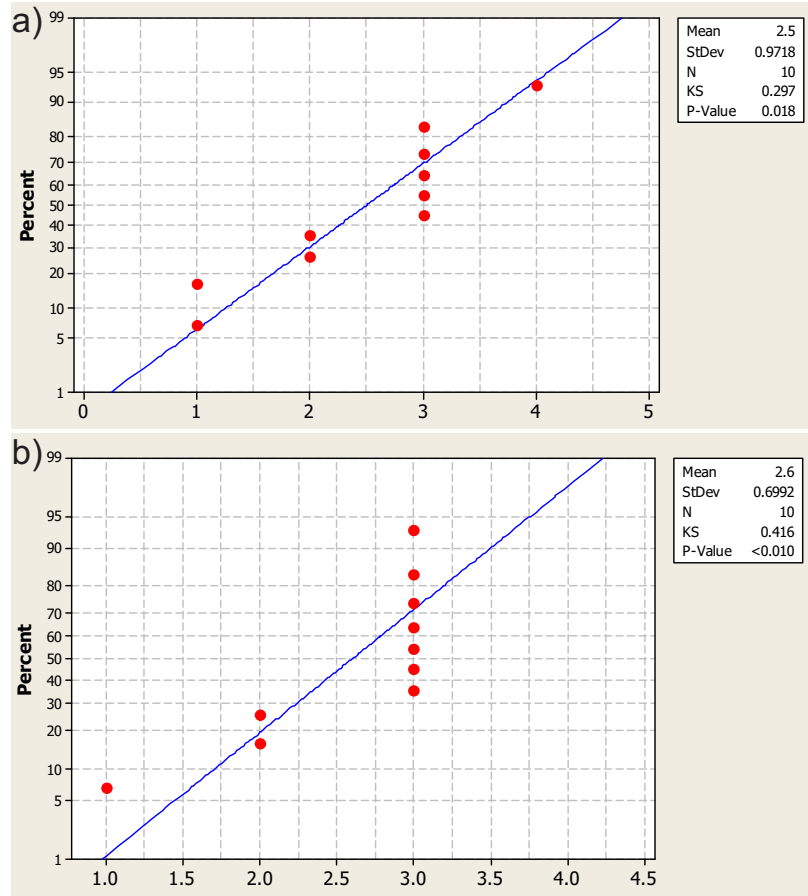

Fig. 2. Statistical interpretation of samples S4 (Unit 1) and S9 (Unit 4) using the Kolmogorov-Smirnov normality test.

ance of a dead embryo, hyperpigmentation of larvae body, a tail's lack of detachment, and the impossibility of head and related parties development.

The comparative embryo-lethality percentage on the studied samples and water dilution is presented in Table 2, and the main normal $v s$. abnormal aspects of embryo developments found in our assay are presented in Fig. 1.

The embryo mortality analyzed according to the Kolmogorov-Smirnov statistical normality test (only the statistically significant results) revealed that the units considered having a water-polluting potential and importance for public health were units 1 and 4 . The statistical results for the provided samples from units 1 and 4 are shown in Fig. 2.

\section{Discussion}

Zebra fish embryos are complete organisms that allow their use as alternatives in acute fish tests for diverse effluent testing [12, 21-23].

Numerous authors have conducted tests concerning the early development stages of zebra fish, all revealing an increased sensitivity of this test to estimate: the maximum acceptable concentration of a toxin [2-4, 6-8], developmental neurotoxicity [24], teratogenicity [5, 23], embryotoxicity $[3,25]$, and/or screening a large number of chemicals $[10,13,14,26]$.

The results we obtained can be considered to be of interest because they bring up-to-date information about the general status of the freshwater sources in geographical regions where there is a possible risk of pollution. In this aim, we are confirming that the establishment of water pollution risk criteria can be ascertained with this test. In this respect some authors have used the zebra fish tests, proposing this analysis as a certain general model for ecotoxicology $[1,7,10-12,21,22]$.

Other researchers conducted tests on zebra fish embryos focusing especially on: pigmentation disorders, effects on heart rate, and teratogenicity of the chemicals, reaching the conclusion that these assays are very useful in the screening tests that can be used in preclinical trials $[5,11,14,25-27]$.

In this respect, we have also observed the presence of acute toxicity main end points such as pigmentation disorders and lack of tail detachment, etc., in water samples from the vicinity of the polluting units. Our study confirmed that zebra fish eggs and embryos could become a valuable model for assessing the risks of chemical substances in the environment due possibly achieving a cheap and precise analysis at a reduced scale, being also an alternative for the adult zebra fish acute tests $[12,17,28-31]$.

As a modern research alternative, we agree with other authors who have appreciated that zebra fish are fully complementary to rodents (especially in the early stages of drug research), and with authors who linked the zebra fish embryo development models to the human embryogenesis which, with the developing of this in vitro model, will be able to substitute and provide relevant results useful to vertebrate research $[1,3-10,14]$.

\section{Conclusions}

The embryonic lethality assessment revealed a link between the numbers of dead embryos at the same concentration for different samples taken from the same water source. The microscopic images of embryos for the acute toxicity main end points and the statistical analysis confirmed that the units found with river-polluting potential were units 1 and 4.

Despite the fact that it is a qualitative method rather than a quantitative one (in this case) we consider that using eggs and embryos is preferable due to its numerous advantages (including that they aren't subject to the legislation for animal protection during experiments) and could be included in the usual methodologies of the interested labs as a routine methodology.

\section{Acknowledgements}

This work was co-financed from the European Social Fund through Sectorial Operational Programme Human Resources Development 2007-13, POSDR 159/1.5/S/ 132765.

\section{References}

1. LANGE M., GEBAUER W., MARKL J., NAGEL R. Comparison of testing acute toxicity on embryo of zebra fish (Brachydanio rerio) and RGT-2 cytotoxicity as possible alternatives to the acute fish test. Chemosphere, 30, (11), 2087, 1995. 
2. LOUCKS E., CARVAN M.J. Strain-dependent effects of developmental ethanol exposure in zebra fish. Neurotoxicol. Teratol., 26, (6), 745, 2004.

3. BRAUNBECK T., BÖTTCHER M., HOLLERT H., KOSMEHL T., LAMMER E., LEIST E., RUDOLF M., SEITZ $\mathrm{N}$. Towards an alternative for the acute fish $\mathrm{LC}_{50}$ test in chemical assessment: the fish embryo toxicity testgoes multi-species - an update. ALTEX, 22, (2), 87, 2005.

4. HILL A.J., TERAOKA H., HEIDEMAN W., PETERSON R.E. Zebra fish as a model vertebrate for investigating chemical toxicity. Toxicol. Sci., 86, (1), 6, 2005.

5. BUSQUET F., NAGEL R., VON LANDENBERG F., MUELLER S.O., HUEBLER N., BROSCHARD T.H. Development of a new screening assay to identify pro teratogenic substances using zebra fish Danio rerio embryo combined with an exogenous mammalian metabolic activation system (mDarT). Toxicol. Sci., 104, (1), 177, 2008.

6. McGRATH P., LI C.Q. Zebra fish: a predictive model for assessing drug-induced toxicity. Drug Discov. Today, 13, (910), 394, 2008.

7. SCHIRMER K., TANNEBERGER K., KRAMER N.I., VOLKER D., SCHOLZ S., HAFNER C., LEE L.E., BOLS N.C., HERMENS J.L. Developing a list of reference chemicals for testing alternatives to whole fish toxicity tests. Aquat. Toxicol. 90, (2), 128, 2008.

8. CHAKRABORTY C., HSU C.H., WEN Z.H., LIN C.S., AGORAMOORTHY G. Zebra fish: a complete animal model for in vivo drug discovery and development. Current Drug Metabolism, 10, (2), 116, 2009.

9. LAMMER E., KAMP H.G., HISGEN V., KOCH M., REINHARD D., SALINAS E.R., WENDLER K., ZOK S., BRAUNBECK T. Development of a flow-through system for the fish embryo toxicity test (FET) with the zebra fish (Danio rerio). Toxicol. In Vitro, 23, (7), 1436, 2009.

10. EMBRY R.M., BELANGER S.E., BRAUNBECK T.A., GALAY-BURGOS M., HALDER M., HINTON D.E., LÉONARD M.A., LILLICRAP A., NORBERG-KING T., WHALE G. The fish embryo toxicity test as an animal alternative method in hazard and risk assessment and scientific research. Aquat. Toxicol., 97, (2), 79, 2010.

11. NAGEL R. DarT: the embryo test with the zebra fish (Danio rerio) - a general model in ecotoxicology and toxicology. ALTEX, 19, (Suppl. 1), 38, 2002.

12. SCHOLZ S., FISCHER S., GÜNDEL U., KÜSTER E., LUCKENBACH T., VOELKER D. The zebra fish embryo model in environmental risk assessment - applications beyond acute toxicity testing. Environmental Science Pollution Research International, 15, (5), 394, 2008.

13. BRANNEN K.C., PANZICA-KELLY J.M., DANBERRY T.L., AUGUSTINE-RAUCH K.A. Development of a zebra fish embryo teratogenicity assay and quantitative prediction model. Birth Defects Research B Developmental Reproductive Toxicology, 89, (1), 66, 2010.

14. ALI S. CHAMPAGNE D.L., SPAINK H.P., RICHARDSON M.K. Zebra fish embryos and larvae: a new generation of disease models and drug screens. Birth Defects Research Part C: Embryo Today, 93, (2), 115, 2011.

15. DIRECTIVE 2010/63/EU, of the European Parliament and of the Council of the European Union. On the Protection of Animals Used for Scientific Purposes. Official Journal of the European Union L276, 233-279, 2010.

http://eur-lex.europa.eu/legal-content/EN/TXT/?uri=celex: 32010L0063

16. TSO (The Stationary Office) Guidance on the Operation of the Animals (Scientific Procedures) Act HC 321, 2000.
London, UK. https://www.gov.uk/government/uploads/ system/uploads/attachment_data/file/228542/0321.pdf

17. MOSNEANG C.L. Means of assessment of water and soil pollution in the vicinity of swine farms. $\mathrm{PhD}$ thesis, USAMVB Timișoara, 2013 [In Romanian].

18. MOȘNEANG C.L., ORDODI V.L., CRISTINA R.T. An analysis of water samples surrounding swine farms in Timiş County - A practical guide. Medicamentul Veterinar/ Veterinary Drug, 7, (2), 56, 2013.

19. MOȘNEANG C.L., GROZEA A., DUMITRESCU E., MUSELIN F., CRISTINA R.T. A correlation between two different species of fish embryos used in a freshwater qualitative pollution test. Romanian Biotechnological Letters, 20, (2), 10352, 2015

20. ISO 15088:2007. Water quality - Determination of the acute toxicity of waste water to zebra fish eggs (Danio rerio) https://www.iso.org/obp/ui/\#iso:std:iso:15088:ed-1:v1:en

21. NAGEL R., ISBERNER K. Testing of chemicals with fish a critical evaluation of tests with special regard to zebra fish. In: Fish Ecotoxicology, Eds. T. Braunbeck, D.E. Hinton, Streit, B. Birkhäuser Verlag, Basel, Switzerland, pp. 338$352,1998$.

22. SEOK S.H., BAEK M.W., LEE H.Y., KIM D.J., NA Y.R., NOH K.J., PARK S.H., LEE H.K., LEE B.H., PARK J.H. In vivo alternative testing with zebra fish in ecotoxicology. Journal of Veterinary Science, 9, (4), 351, 2008.

23. SELDERSLAGHS I.W., VAN ROMPAY A.R., DE COEN W., WITTERS H.E. Development of a screening assay to identify teratogenic and embryotoxic chemicals using the zebra fish embryo. Reprod. Toxicol., 28, (3), 308, 2009.

24. TON C., LIN Y., WILLETT C. Zebra fish as a model for developmental neurotoxicity testing. Birth Defects Research Part A: Clinical and Molecular Teratology, 76, (7), 553, 2006.

25. YANG L., HO N.Y., ALSHUT R., LEGRADI J., WEISS C., REISCHL M., MIKUT R., LIEBEL U., MÜLLER F., STRÄHLE U. Zebra fish embryos as models for embryotoxic and teratological effects of chemicals. Reprod. Toxicol., 28, (2), 245, 2009.

26. WEIGT S., HUEBLER N., BRAUNBECK T., VON LANDENBERG F., BROSCHARD T.H. Zebra fish teratogenicity test with metabolic activation (mDarT): effects of phase I activation of acetaminophen on zebra fish Danio rerio embryos. Toxicology, 275, (1-3), 36, 2010.

27. KIMMEL C.B., BALLARD W.W., KIMMEL S.R., ULLMAN B., SCHILLING T.F. Stages of embryonic development of the zebra fish. Dev. Dynam. 203, (3), 253, 1995.

28. SCHULTE C., NAGEL R. Testing Acute Toxicity in the Embryo of Zebra fish, Brachydanio rerio, as an Alternative to the Acute Fish Test: Preliminary results. ATLA, 22, 12, 1994.

29. EURL ECVAM (European Commission Joint Research Centre Institute for Health and Consumer Protection EU Reference Laboratory for Alternatives to Animal Testing). Recommendation on the Zebra fish Embryo Acute Toxicity Test Method (ZFET) for Acute Aquatic Toxicity Testing, June 2014, Italy (doi: 10.2788/87475). https://ec.europa.eu/jrc/sites/default/files/eur_26710_eurl ecvam zfet recommendation online.pdf

30. OECD. Guideline 203. Fish - Acute toxicity test. http://www.oecd.org/chemicalsafety/risk-assessment/ 1948241.pdf

31. OECD. Guideline 210. Fish - Early-life stage toxicity test. http://www.oecd-ilibrary.org/environment/test-no-210-fishearly-life-stage-toxicity-test_9789264070103-en 
